\title{
CONCLUSION
}

\section{Some Implications of the Study}

\author{
1. DEWEY AND THE
}

\section{Foundationalist/Anti-Foundationalist Controversy}

The interpretation of Dewey's metaphysics presented in the preceding chapters has a direct bearing on a much-discussed topic in contemporary philosophical literature. I am referring to the dispute between foundationalists and anti-foundationalists, especially as it has been articulated in the works of Richard Rorty. Rorty is a prominent defender of the anti-foundationalist side of this issue, of course, but he is particularly important with respect to my analyses because he enlists Dewey's support in his enterprise. Rorty admires Dewey as someone who encouraged the promulgation of "a nonepistemological sort of philosophy" ( $\left.\mathrm{MN}_{3} 81\right)^{1}$ by undermining "philosophical realism" (MN 382). A list of "the richest and most original philosophers of our time" (CP 51$)$ would include Dewey along with Heidegger and Wittgenstein. These thinkers are praised as forward-looking individuals who were effective at criticizing the tradition (CP 35), while helping philosophy to break free from its "outworn" (MN 12) past.

Such high praise is counterbalanced by the admission that there are weaknesses in Dewey's philosophy, the most significant of which speaks directly to the line of interpretation I have been defending in this book. Dewey did well, according to Rorty, until he was "sidetracked into doing 'metaphysics' " (CP 82). The very expression "naturalistic metaphysics" (CP 81) is a contradiction in terms because it seeks to combine the empirical with the ahistorical. This "bad ('metaphysical')" (CP 214) side of Dewey is most evident when he seeks to redescribe nature and experience (CP 85). Dewey failed here to carry his criticism of the tradition to its proper conclusion. By attempting to provide descriptive characteristics of experience and nature he was backsliding and engendering conflict "according to the old rules" (CP 35). On this view Dewey did not realize that 
his criticisms of the philosophical tradition opened the way to what Rorty calls a "post-Philosophical" (CP xxi) culture. Disappointingly, Dewey went about doing what philosophers have always done, providing formulations of experience, nature, and value which are thought to be more accurate than the erroneous views of their predecessors (CP 79-80). Rorty wants to claim Dewey as an "edifying" non-foundationalist philosopher, but "Dewey's mistake" (CP 85), his wrongheaded excursion into metaphysics, is a great embarrassment to such an interpretation. Rorty thus dimisses it as a lapse on Dewey's part. The real Dewey, covered over by such expendable texts as Experience and Nature, ${ }^{2}$ has no need for such an undertaking. Indeed, metaphysics is something that "Dewey's own view of the nature and function of philosophy precludes" (CP 77).

To sort out the confusions, misunderstandings, and misrepresentations Dewey suffers at the hands of Rorty, I shall review some of the main lines of my interpretation in light of his claims. The proper understanding of what metaphysics involves along with Rorty's views on this matter were taken up in the Introduction. I shall not repeat them here. My remarks will be limited to a commentary on the attempted appropriation of Dewey to the antifoundationalist camp.

We must begin by recognizing that the foundationalist/antifoundationalist split is not a problem that can be solved on Deweyan lines. The very formulation of the antithesis is foreign to the spirit of what Dewey sought to accomplish. We saw in Chapter 3 how he refused to align himself with either the realist or the idealist schools. We also saw how the influence of Darwin led Dewey to realize that the very phrasing of controversies such as that of mechanism vs. teleology prevented a satisfactory resolution of them. Dewey was a naturalist who stressed the interaction of existents with their environments as a primordial trait of existence. Those polarized oppositions which resulted from an alternative (usually dualistic) ontology had to be restated in light of the more accurate ontological analysis. They were, as we saw, not so much solved as dissolved.

The foundationalist and the non-foundationalist positions offer another instance of the same procedure. They arise in the context of "epistemology," in the derisive sense Dewey gave to that term. The foundationalist viewpoint is constructed on assumptions derived 
from Plato and Kant. The Platonic division into two realms of being and two subsequent levels of cognition, when combined with the Kantian endeavor to certify the adequacy of knowledge claims, provides the background against which foundationalists operate. They ask the Platonic question "What differentiates knowledge from mere belief?" and go off in search of foundations that will provide the criteria for categorizing certain claims as real knowledge. One response common to foundationalists, according to Rorty, is that the criteria involve "reference to an object" (MN $\left.{ }_{5} 6\right)$. The image best exemplifying this view is that of a mirror that accurately reflects objects. Such a mirror containing the correct reflections becomes the "touchstone for choice between justified and unjustified claims" (MN 212). Rorty summarizes the foundationalist position in the following way: (a) The original impulse is that of "having our beliefs determined by being brought face-to-face with the object of the belief" ( $\mathrm{MN}_{163}$ ); (b) improvements in knowing result from improvements in the accuracy of representations within the mirror of nature ( $\mathrm{MN} 163)$; $(c)$ "Then comes the idea that the way to have accurate representations is to find, within the Mirror, a special class of representations so compelling that their accuracy cannot be doubted" ( $\mathrm{MN}_{163}$ ). These representations, innate ideas, sense data, the structure of language, or Platonic forms, and the like, provide the boundaries of knowledge. They act, Rorty says, as "constraints," imposing "frameworks beyond which one must not stray, objects which impose themselves, representations which cannot be gainsaid" (MN 315).

Without the dualistic assumption of a knowing subject that is both distinct and separate from a known object there would be no context within which such questions as "Is knowledge possible?" "How are knowledge claims to be justified?" or "What are the most accurate representations?" would make sense. If there is no separate substance called "mind" to which objects are "presented" or "given," then the issue of providing justifications for asserting that certain representations are more accurate reflections of a disparate object than others does not arise. Such questions, indeed, do not interest Dewey in the least. The whole vocabulary in which such topics are phrased has been revised by what he called his "Copernican Revolution," which he described as: 
The old centre was mind knowing by means of an equipment of powers complete within itself, and merely exercised upon an antecedent external material equally complete in itself. The new centre is indefinite interactions taking place within a course of nature which is not fixed and complete, but which is capable of direction to new and different results through the mediation of intentional operations [QC 232].

By suggesting this Copernican Revolution Dewey has completely altered the context in which gnoseological questions are raised. The whole vocabulary in which such topics have been phrased under the influence of Cartesian and Kantian philosophies now has to be revised. After Dewey, philosophical questions have to be reformulated in the same way as astronomical questions had to be reformulated after Copernicus.

This is not to say that Dewey ignores reflection, inquiry, and cognition. His novel ontological orientation simply leads him to a concern with different questions in relation to knowing. Consistent with his recognition that events are temporal is his rejection of the textbook notion that there are rigidly fixed philosophical problems that have plagued thinkers from Thales to the present. The very formulation of questions depends on an ontological orientation. Dewey has opened the door to post-modern philosophy by revealing the ways in which the modern map of generative ideas was flawed, sterile, and truncated. His metaphysics, as I have interpreted it, articulates the lineaments of existence in a manner which transforms the very manner in which philosophical questions are to be posed.

Dewey is not interested, for example, in ascertaining whether knowledge is possible. Intelligence in the service of modifying the environment/organism interaction is an ongoing and obvious fact. What he seeks to discover is the manner in which human beings can increase, improve, and manipulate what is known in order to attain more security, harmony, and satisfaction. Dewey wants to examine "how we think" so that we may better attain this kind of security, harmony, and satisfaction. The question of justifying knowledge claims by suggesting that they are grounded, or have their foundations, in something like the "directly evident" or the "selfpresenting"s is a relic of a previous and outmoded philosophical era. It is not a relic because he supports the kind of anti- 
foundationalist view Rorty espouses. Rather, the entire controversy must be viewed as artificial because it is based on an erroneous metaphysics, one that separates matter and mind.

Rorty's claims notwithstanding, Dewey's own orientation cannot be properly understood apart from his new metaphysics as I have described it in this book. Any attempt at understanding Dewey while not appreciating the ontology he worked out in his writings from 1925 onward will lead to the claim that there are two Deweys: one who is a foundationalist, and one who is not. There exist many Deweyan texts which if taken in isolation can provide solace to both the foundationalist and the anti-foundationalist. The only avenue left open for Rorty, if he wishes Dewey as an ally, is to dismiss as unimportant those texts that do not support his view. This is of course exactly what he does. Such a procedure, the selective appropriation of an earlier thinker's writings, is entirely defensible as a later thinker weaves the strands of a new synthesis. But what is not defensible is the coupling of this selective appropriation with the claim that the real Dewey is being brought out. It is one thing for a scholar to say "there are many aspects of Dewey's thought that I find accurate and enlightening." It is another matter entirely for the same scholar to claim that "those aspects with which I agree represent Dewey more accurately than he represented himself." Yet it is an assertion like the latter, absolutely unjustified as an historical or interpretive statement, which Rorty makes.

A thorough reading of Dewey would lead to a different conclusion: that his great achievement was to reformulate entirely the philosophical orientation within which such controversies as that between the foundationalists and the anti-foundationalists could take place. Dewey's importance for subsequent thinkers resides in this very attempt at reformulating philosophical problems. He does indeed criticize the tradition in the manner for which Rorty praises him, but he does so in order to reconstruct not deconstruct the philosophical heritage. Chapters 5 and 6 of the present book reveal this with special clarity.

If we ask how exactly it is that Dewey reconstructs the tradition, three major prongs of his analysis must be re-emphasized. (a) Interaction of existents within situations is the basal descriptive fact that philosophers must recognize. Situations are not constructed out of separate, disconnected, individual elements that somehow have re- 
lations superimposed on them. Relations are a primary or archaic (in its etymological sense) factor. This is a constant Deweyan theme from his Hegelian period onward. (b) Vital experience ${ }^{4}$ is neither wholly nor primarily cognitive. Dewey denied the ubiquity of the knowledge relation from his experimental phase onward and, like his younger contemporary Heidegger, rejected the identification of ov่oía with ióéa. ${ }^{5}$ Ordinary experience is wider than cognition, including, as it does, moral and aesthetic dimensions. Dewey's criticisms of realism and idealism, discussed in Chapter 3, are based on the recognition of this fact. $(c)$ Forms must be understood in terms of possibility. The possibility/realization or logiscibility/accrual distinction worked out in his naturalistic period is what allowed Dewey to reconstruct traditional views in light of scientific achievements. If these three doctrines are properly appreciated, it will be possible to understand how Dewey was able to avoid the excesses of the earlier realistic philosophies, while not succumbing to the reactive excesses of abandoning the connectedness or grounding of ideas in nature. The articulation of the contribution Dewey can make to the foundationalist/non-foundationalist dispute will evolve as an outgrowth of these three points.

Rorty's writings on this issue are fertile, exciting, and provocative. He is especially to be praised for delivering one more (perhaps final) blow to the edifice of epistemology-centered philosophies that have been dominant since the time of Descartes. But his own response to foundationalism, a blend of historicism and coherentism, offers only one, and perhaps not the most suitable, alternative to the Cartesian and Kantian traditions he is seeking to overcome. His suggestion that "conversation" and social practice replace the confrontation with objects suggested by previous philosophers does offer a viable alternative to foundationalism. Still, it is only one alternative. More important, given the line of research undertaken in this book, it has little in common with the philosophy of John Dewey. This is significant because Rorty, as I have already made clear, claims to be carrying on the type of endeavor Dewey began. That endeavor, properly understood, opens a path that allows philosophers to avoid the errors of past epistemologies while preserving the integrity and connection of humans with the natural world. This view cannot be properly grasped, however, if certain central doctrines within his philosophy are excised. 
Rorty claims that Dewey was a leader in the undermining of philosophical realism, and he goes on to build an interpretation of Dewey as an unmitigated non-realist. But such an interpretation is not at all sensitive to the nuances in Dewey's thought. The argument in Chapter 3 describing the objections Dewey marshaled against both realism and idealism must be recalled if he is to be interpreted correctly. What must be kept in mind in relation to realism is that only certain versions of that doctrine were criticized. He was careful to single out "presentative," "analytic," and "epistemological" realisms as discredited positions. These three varieties of realism share one untenable assumption: in a knowledge situation an antecedently existing object is simply presented to a knower. A knower, Dewey well realized, is no simple spectator, taking in (or mirroring) the entities that make up the natural world. The "metaphysics of presence," that bette noire of the deconstructionists, Dewey had already disposed of in the early decades of this century. Knowing involves an objective that can be attained only by means of some manipulation or experimentation with the antecedently existent situation. The knower has to do something to attain knowledge. This was what Dewey meant to emphasize by the label "instrumentalism." Knowing and doing must not be interpreted as antithetical activities. In Chapters 2 and 3, I explained this view and indicated how a careful appreciation of the idiosyncratic manner in which Dewey uses the term "object" is necessary for a proper grasp of what he is saying. Nonetheless, it is clear that, as far as Dewey is concerned, knowing does not simply mirror beings.

Dewey could be aligned with the anti-foundationalists if this represented his position in its entirety. But it does not. Dewey's view cannot be classified as supporting either foundationalism or Rorty's brand of non-foundationalism. If any term describes his orientation, it is "eventualist." Events themselves set the boundaries of reflection and inquiry for Dewey. The direction and effectiveness of inquiry are guided by the situation out of which the need for inquiry arises. The outcomes or eventuations of inquiry must then be examined and adjudicated by reference to the situations out of which they arose. The link between nature and human nature is not severed in Dewey's thought from his Hegelian period onward. He could never have written an article with the title which Rorty gave to one of his efforts, "The World Well Lost" (CP $3^{-18}$ ). Indeed, he spent his 
whole philosophical life trying to articulate properly the manner in which humans and the natural world are related.

The importance of experience, interaction, and possibility can be ascertained at this point. Dewey is difficult to understand because he articulates a novel metaphysics. Commentators on his works who overlook the centrality of these three doctrines cannot gain a proper understanding of his thought. I shall begin with some remarks on experience and interaction while pursuing the topic of possibility later on.

Readers who persist in seeing subject and object or individual and environment as primordial data will misinterpret Dewey badly. The primal, basal situation involves complex multirelational circumstances $^{6}$ (if I may use this word in its etymological sense as the totality of surrounding things). Ingredients within the circumstances, such as individuals, qualities, hindrances, activities, whatever someone might consider to be "simple" or "self-evident," can be focused on by choice. They are, Dewey says, "selected for a purpose" (EN 35). Cognition involves this kind of refined, selective activity. Life experiences, those interactions which comprise most of our lives, are to a great degree non-cognitive. They concern use and enjoyment. It is only when problematic situations arise that reflection and inquiry are brought to bear on experience. Such problematic situations can come about for any number of reasons: changes might occur which upset the usual rhythm of use and enjoyment; questions arise out of curiosity as to what things are like or how they work; people seek ways to avoid certain aspects of experience while extending and securing others. Warranted assertibility results when the appropriate method for resolving problematic situations is employed. Dewey had learned from Morris to avoid the vices of epistemology-centered idealisms. Thus he does not consider the questions "How is knowledge justified?" and "Is anything antecedently given or directly evident or self-presenting?" to be especially burning issues. The significant question is, rather, how do we go about "bettering and enriching the subject-matters of crude experience" (EN 29). How, starting from life experience in its complexity, do we go about securing the "possibility of intelligent administration of the elements of doing and suffering" (EN 29)?

Rorty asserts that the non-foundationalist seeks an "airtight case," not an "unshakeable foundation" (MN 157). Dewey does not seek 
an unshakeable foundation; nor does he consider the appropriateness of his approach to be judged on the basis of "conversation between persons, rather than a matter of interaction with non-human reality" (MN 157). Dewey could never assent to such a claim because of the manner in which interaction with environment is denigrated. While Dewey does not consider warranted assertibility to be the outcome of scrutinizing, examining, or otherwise interacting with non-human reality as represented for example by a Platonic realm of Forms, he nonetheless emphasizes forcefully that interactions within a situation are the sources of inquiry and the touchstones of its success or failure. Dewey does not spend his philosophical time examining such issues as the structure of "mind," or engaging in "conceptual analysis," but he does assert the need for awareness of the context, limitations, and direction provided by the natural world. "The exacting conditions imposed by nature, that have to be observed in order that work be carried through to success, are the source of all noting and recording of nature's doings. They supply the discipline that chastens exuberant fancy into respect for the operation of events, and that effects the subjection of thought to a pertinent order of space and time" (EN 100).

There are no foundations in Dewey if by foundations we mean some form of a self-evident given. But inquiry is not self-enclosed. It reaches beyond itself and is to be judged on how well the eventuations, objects, of inquiry have resolved problematic situations. For Dewey, the forms which accrue as the outcomes of inquiries have come out of a particular set of circumstances, and they are to be judged in relation to that context. There are no unshakable, a priori, or apodictic foundations, but knowledge can be considered meaningful only by referring to the interactions with the natural world of which humans form a part.

Interaction is thus a term which points beyond inquiry for Dewey. It is both what occasions reflection and what adjudicates it. Such a teaching would appear to bring Dewey dangerously close to the realisms he so steadfastly opposed in his career. The next dimension of Dewey's metaphysics that I wish to discuss, "possibility," reveals the manner in which he is able to distance himself from those realisms. Trendelenburg, as I indicated in Chapter 1, had sought to overcome the polarities in modern philosophy by reintroducing the Aristotelian doctrine of potentiality and actuality. Dewey concen. 
trated on this distinction in his favorable interpretation of Leibniz. This seed, planted during his idealistic period, reached full maturation during his naturalistic phase.

If the interpretation presented in this book is correct, forms are neither given (as some foundationalists might claim) nor denied (the Rortyan non-foundationalist view). There is no simple either/ or for Dewey. It is the doctrine of possibility which allows the actual complexity of existence to be delineated. Rorty appears to have oversimplified the options within philosophy. His depiction of the foundationalist/anti-foundationalist dispute embodies a false dilemma: either Plato or Protagoras. Dewey, on the other hand, embraces neither the correspondence theory nor the coherence theory. His view breaks out of these molds altogether. Rejecting correspondence to "objects" that existed prior to inquiry, he embraces in a significant sense "grounding" in the natural world. So prominent is this aspect in his thought that one leading Dewey scholar has claimed that "it is hard to imagine a theory of ideas more rigorously controlled by the nature of objects than this one [Dewey's]."7

To express accurately the way in which a proper understanding of possibility allows Dewey to overcome the constraints inherited from the modern tradition in philosophy, I shall not construct an imaginary community of Antipodeans but refer in a more mundane, concrete, and realistic manner to a famous contemporary of Dewey's, the plant breeder Luther Burbank. Here was an individual who worked marvels with his cross-breedings. The reflections he has left us on his work offer an opportunity for elucidating Dewey's teachings. The three elements of the Deweyan analysis mentioned above must be kept in mind as we examine Burbank's example: $(a)$ primary experience is wider, more inclusive than cognitive reflection; $(b)$ all experience grows out of interactions; ${ }^{8}(c)$ forms are possibilities that are realized as a result of inquiry. These are familiar doctrines which have been exposed and commented on in the previous seven chapters. I am restating them here even at the risk of being repetitious because they are so crucial to a correct interpretation of Dewey's philosophical orientation.

The Burbank citation is one in which he describes how some of his "most important and valuable work" was with plums. The occasion for this effort was the fact that the plum, though consumed and 
enjoyed, was, prior to his breeding experiments, "small, usually acidic, generally unfit for shipping, often with a large stone."

I wanted to get a plum that would ship ... a plum that would be beautiful and delicious, a plum that would be large, a plum for canning, a plum with a small pit or none at all, and so on. My designs were pretty carefully worked out. For instance, as regards the shipping plum. The plum developed to be picked from the tree and eaten right there, or within a few hours in the house, was quite a different thing from the plum that could be picked, packed, shipped, delivered maybe thousands of miles away, unpacked, sold, carried home, and finally eaten fresh. . . . And this couldn't be acquired by accident or chance-it had to be studied and the specifications pretty carefully written. ${ }^{9}$

All the ingredients for an accurate interpretation of naturalistic metaphysics and inquiry as Dewey conceives them are included in this passage. There is, to begin with, the original situation of primary, vital, ordinary experience. This provides the milieu which occasions Burbank's efforts. Use and enjoyment predominate in this milieu. Humans find themselves in an environment which includes a certain fruit, the plum. This fruit is consumed and enjoyed. It provides sustenance and refreshment. The plum is thus a natural good which is selected, preferred by a number of individuals. Now, out of this original, not yet cognitive, experience there arise issues that call forth cognition. Change and improvement are important factors in human life. Direct, concrete experience gives way to a situation that is "tensional" or "problematic" when certain questions arise. The people enjoying the plum might, for example, wonder how they can go about enhancing the qualities of the plum while minimizing its deficiencies. They might, in addition, seek out ways to share the fruit with their fellow-human beings on a wider scale than is currently possible.

Questions like these transform an experience that was not primarily cognitive into one which seeks the direction and control that knowledge can bring. The concrete experience of use and enjoyment has been altered. The kinds of issues Burbank raised affect the rhythm and equilibrium of ordinary experience. Whereas the original plum was accepted as a fruit of a certain size, with a certain level of acidity, and a large pit, those characteristics are now brought 
into question. Use and enjoyment within the direct, primary experience no longer suffice. An attempt is being made to improve the ordinary experience. It would be preferable to enjoy a larger, sweeter, seedless plum. Instead of the original plum enjoyed by a limited number of people because it did not ship well, it would be helpful to produce one that could travel thousands of miles, yet remain attractive to the palate. Inquiry is, for Dewey, an attempt to resolve problems such as these. The ends sought could not be achieved, as Burbank remarked, "by accident or chance." The task of this particular inquiry was well defined: to investigate by means of experimentation whether certain varieties of plums satisfying the new criteria could be brought into existence. Knowledge in this case does not strive to ascertain antecedently existent reality, but attempts to attain certain objectives. Burbank did not prejudge his experiments as failures because of a priori constraints and limitations. He did not view his efforts as necessarily condemned to failure because there was a fixed form of plum which could not be altered. He simply undertook, by experimenting with various parent stocks, to select for the qualities he sought. He pressed the plum species to reveal its possibilities and produce new forms of the fruit. The varieties resulting from this endeavor were structured in certain ways. They possessed characteristic patterns of appearance and behavior. They were, in other words, formed entities.

Once these had been produced, their "truth" and "value" could be determined by examining in what ways they satisfied the aims set forth at the beginning of the inquiry. There is only one sure way of deciding whether a plum can travel a thousand miles, be stored on a grocery shelf, brought home, and remain not merely edible but tasteful: send some of the new varieties on just such a journey. The problematic situation arose within a context, and the success or failure in resolving it will be judged by a return to that context. This indicates one of the ways in which Dewey could be said to stand with the foundationalists. For him, inquiry is indeed judged by more than the Rortyan criterion of "what society lets us say" (MN 174). The new plum has restored equilibrium where there was tension if indeed it can be shipped thousands of miles, placed on a supermarket shelf, brought home, and at that point reveal itself as soft, juicy, and sweet. Success in inquiry is inextricably connected to interactions between humans and their environments. No theory 
which severs this connection can claim Dewey as one of its adherents.

Dewey's sensitivity to the nuances of possibility inherent in existential situations serves him particularly well in this respect. The forms, as he understands them, do not exist prior to their eventuation in natural beings. There can thus be no correspondence to antecedently existing forms as the touchstone of truth and certainty. At the same time the forms (as in the case of the plum varieties Burbank produced) are "logiscible," capable of being realized. On that account, all talk of structure and essence should not be abandoned. This is a position which Rorty suggests when he chides Sartre for not pushing further his insight that there is no human essence. Sartre, he says, should have "followed up his remark that man is the being whose essence is to have no essence by saying that this went for all other beings also" (MN ${ }_{361-62 n 7}$ ). Dewey, true to his reconstructionist attitude, wishes to reject only what is untenable in older philosophies. That any pre-evolutionary doctrine of forms falsifies existence is a view Dewey accepts; that any doctrine of forms is false is an overreaction Dewey is careful to avoid.

By concentrating on contextually centered analyses, by focusing on problems of securing and enhancing values, and by recognizing the importance of formulating a metaphysics for such an endeavor, Dewey reconstructed in a large-scale manner the philosophical heritage that gave rise to problems such as the foundationalist/antifoundationalist controversy. He cannot, I must repeat once again, be allied to either side of this controversy. His whole endeavor, from the Hegelian period onward, was to reveal the manner in which such philosophical problems had been inaugurated and sustained by erroneous ontological assumptions. Dewey is significant in relation to the question of foundationalism $v$ s.non-foundationalism, but it is as someone who restructured our very way of looking at this entire topic.

\section{On Interpreting Dewey}

The misrepresentation of Dewey by a sympathetic scholar like Rorty raises the question of how it could happen that Dewey would be so badly misunderstood. This topic deserves a few comments since Dewey is a thinker who can readily be misinterpreted. Because of the great variety of philosophical traditions that were 
ingredients in his ultimate synthesis, Dewey's writings present special problems. It is possible on the basis of having read some of these texts to impute to him various positions that he did not hold at all. I have dealt at length in this book with critics who accuse him of being an idealist. He could also be misrepresented as a realist, a Lockean, an Hegelian, or, as I have mentioned, as both a foundationalist and a non-foundationalist. Such interpretations could all call on certain texts for support. Dewey interpretation cannot then be simply a matter of reading a substantial portion of his writings and selecting extracts that are said to typify his orientation. Views imputed to him on this basis are more than likely to be misleading, if not entirely false. Deweyan scholarship needs to make a special effort if it is to portray this thinker's positions accurately. That effort will involve both a strenuous philosophical reorientation and a sensitivity to certain factors in his writing style and evolution as a thinker.

Much of the difficulty surrounding a proper interpretation of Dewey rests on one important fact: he significantly altered the very assumptions according to which philosophers were accustomed to proceed. His interpreters must vigilantly seek to avoid reading their own assumptions into Dewey's texts. Anyone, for example, who claims to find a discussion of the is/ought or mind/body questions along typical (modern, dualistic) lines in Dewey's writings has failed badly to learn from the Deweyan corpus. The mind/body problem and the is/ought distinction are among the issues that a Deweyan philosophy regards as associated with an earlier, erroneous ontology. Admittedly, it is a difficult task to understand Dewey properly when our very language embodies polarities (subject/object, knowing/ doing, individual/environment) as givens of experience which Dewey argues are "takens," selected for a particular purpose. Yet, until thinkers begin to conceive of situations and circumstances rather than individuals as primary, Dewey's insights will remain either hidden or distorted by the prism of earlier assumptions.

Unfortunately, this theoretical problem is compounded by the notorious difficulty of expression in Dewey's works. James Gouinlock, who knows Dewey's writings as well as anyone, admits quite readily that "Dewey never won anȳ prizes for clarity." He goes on to say that there are many "obscure, ill-expressed, and confusing 
passages in his works; and a scholar might read them in various ways." 10 There are, however, certain safeguards to maximize the chances of a correct interpretation of Dewey.

First of all, no interpreter can come to a proper understanding of Dewey's philosophy unless two crucial aspects of his career and writings are recognized. Dewey scholars must learn the lesson that Jaeger taught with regard to Aristotle: the philosophy in question is a developmental one. It is a position that has evolved through time. Dewey's thinking underwent a considerable amount of modification as his career progressed. Secondly, many of his writings are of a polemical nature. They cannot be read as texts conceived in isolation from burning philosophical controversies. Those same controversies may no longer arouse the passions they once did, but Dewey must be seen as a thinker engaged in active disputations with other philosophers. No serious analysis of Dewey's thought can afford to overlook these two considerations.

The developmental aspect is significant for critics and supporters alike. Both the critic wishing to accuse Dewey of error or inconsistency, and the supporter arguing that a particular position accurately reflects Dewey's thinking, must take account of the fact that his was an evolving, continually developing philosophy. ${ }^{11}$ Only then can the criticism or exposition be justified. The polemical aspect is closely interwoven with the developmental. Dewey tends, as is not uncommon in the heat of controversy, to overstate his position. This means that if only selected texts are studied, with reference neither to their place in Dewey's career nor to the particular controversy occupying him, his position can easily be misunderstood. Would-be interpreters of Dewey should ask themselves two questions when confronting his texts: (a) At what stage in Dewey's evolution does this text occur? and $(b)$ Has the controversial climate in which this text was prepared perhaps led Dewey to employ exaggerated formulations?

The care and work needed for an accurate reading of Dewey does, however, repay the effort. Here is a philosopher who touched, in an original and provocative way, a variety of significant philosophical disciplines from logic to the philosophy of culture, and whose writings are of such a nature that they tend to encourage further constructive effort rather than static satisfaction with the pronounce- 
ments of a master. There are a few special characteristics of the Deweyan corpus that are especially significant in this regard. I should like to end by identifying them.

The most prominent among these is Dewey's attitude toward other disciplines. It is an attitude best described by the adjective irenic. Dewey sought to overcome the isolation of philosophy from the natural sciences, the social sciences, literature, and art. New discoveries or productions in these areas he did not fear as threats to an established and unchangeable philosophical system. They were, rather, welcomed as opportunities to increase meaning and understanding, to secure further goods, and to enhance the occasions for consummatory experiences.

Another characteristic is his experiential approach to philosophical problems. He did not begin with the pronouncements of previous philosophers. Instead, his procedure was to confront the experienced world directly. He never sought to fit the facts of experience into preconceived schemas (not even the ones he had set forth). The virtue which is required if such an orientation is to bear fruit, and which Dewey possessed, is courage: the courage to be honest in dealing with philosophical problems, even if this means modification of previously held positions. This is a trait which Dewey shared with one of his favorite philosophers, Plato. The only difference between the two men would appear to be that the Plato who wrote the Sophist and the Parmenides was more interested in retrogressive self-reflection than Dewey, whose main concern was to move forward.

Finally, in a more specific sense, Dewey is to be commended for his attempt to work out a metaphysics at the very time the antimetaphysical propaganda of the logical positivists was beginning to have an effect on philosophy in English-speaking countries. To be sure, there are limitations that adhere to Dewey's formulated positions. But, in many respects, these result from the fact that, in important ways, Dewey was a pioneer breaking new ground. This willingness of his to explore new ontological ground stands as an example of his philosophical courage. He deserves recognition not only as someone whose ontological analyses reached a certain level of achievement, but, more significant, considering the neo-positivist impact on Anglo-American philosophy, as one who undertook ontological analyses at all. 
NOTES

1. References to Rorty's Philosophy and the Mirror of Nature (MN) and The Consequences of Pragmatism (CP) will be given in parentheses in the text.

2. "I myself would join Reichenbach in dismissing classical Husserlian phenomenology, Bergson, Whitehead, the Dewey of Experience and Nature, the James of Radical Empiricism, neo-Thomist epistemological realism, and a variety of other late nineteenth- and early twentiethcentury systems" (CP 213-14).

3. These two expressions are from a defender of the foundationalist position, Roderick Chisholm. The second is a later, emended version of the first. See The Foundations of Knowing (Minneapolis: The University of Minnesota Press, 1982), p. 26.

4. Many confusions engendered by Dewey's use of the term "experience" could have been avoided if commentators had paid attention to the adjectives with which Dewey qualifies this term. In the first chapter of EN the following are among the list of qualifiers used: "concrete" (p. 39), "direct" (p. 23), "primary" (p. 23), "gross" (p. 24), "ordinary" (p. 17), "crude but total" (p. 19). The original version of the first chapter also included "coarse and vital" (p. $3^{67}$ ) as a way of expressing what Dewey intended.

5. Martin Heidegger, "Plato's Doctrine of Truth," trans. John Barlow, in Philosophy in the Twentieth Century III, edd. William Barrett and Henry Aiken (New York: Random House, 1962), p. 267.

6. Jose Ortega y Gasset has brought the word "circumstance" into the universe of philosophical discourse. "All life means finding oneself in 'circumstances' or in the world around us. For this is the fundamental meaning of the idea 'world.' The world is the sum total of our vital possibilities. It is not then something apart from and foreign to our existence; it is its actual periphery" (The Revolt of the Masses [New York: Norton, 1932], p. 44). Dewey, seeking an appropriate term to indicate his philosophical orientation, had attempted to introduce the Latin word res during his experimental phase: "Philosophers in their exclusively intellectual preoccupation with analytic knowing are only too much given to overlooking the primary import of the term 'thing': namely, res, an affair, an occupation, a 'cause'; something which is similar to having the grippe, or conducting a political campaign, or getting rid of an overstock of canned tomatoes, or going to school, or paying attention to a young woman:-in short, just what is meant in non-philosophic discourse by 'an experience' "(MW X 322-23).

7. James Gouinlock, "Pragmatism Reconsidered," the Roy Wood Sellars Lecture delivered at Bucknell University, April 18, 1983. 
8. 'In other words, in its ordinary human usage, the term 'experience' was invented and employed previously because of the necessity of having some way to refer peremptorily to what is indicated in only a roundabout and divided way by such terms as 'organism' and 'environment,' 'subject' and 'object,' 'persons' and 'things,' 'mind' and 'nature,' and so on" (MW X 324).

9. The Harvest of the Years (Boston \& New York: Houghton Mifflin, 1927), p. 81.

10. "Pragmatism Reconsidered,"

11. The importance of recognizing this fact can be illustrated by the case of Stephen Pepper, who was at once a supporter and a critic of Dewey's. Pepper was a pragmatist who, in the early ' 3 os, noting the lack of work in pragmatic aesthetics, had begun to research the topic in Dewey's writings. When AE appeared, Pepper read it avidly. He noted that Dewey had included the elements he had thought significant, but to his surprise he found him making many assertions "which I should have thought Dewey would rather have bitten his tongue than to have said." This side of Dewey's presentation, which Pepper had not foreseen at all, so predominated that Pepper finally concluded in favor of his own aesthetic theory as the truly pragmatic, whereas "it was Dewey who had here gone astray." Whether Pepper's harsh judgment is correct is not a point on which I am prepared to decide. What I do wish to point out is that we have here, in the very fact of comparing Dewey's positions at two stages, an indication of how important it is to recognize the developmental character of his philosophy. See Pepper's "Some Questions on Dewey's Aesthetics." 